\title{
Re-orienting occupational therapy: Embracing generative disruption and revisiting a posture that acknowledges human dignity
}

\author{
*Roshan Galvaan, BSc (OT)(UCT); MSc OT (UCT); PhD OT (UCT). https://orcid.org/0000-0003-00 I4- I842 \\ Professor, Division of Occupational Therapy, Inclusive Practices Africa Research Unit, Department of Health and Rehabilitation Sciences, \\ University of Cape Town, South Africa.
}

Tania Rauch van der Merwe, B.OT (UFS); M.OT (UFS); PhD (UFS). https://orcid.org/0000-0002-575 I-2707 Senior Lecturer, Department of Occupational Therapy, School of Therapeutic Sciences, Faculty of Health Sciences, University of the Free State, Bloemfontein, South Africa.

Background: Amidst the Covid-19 lockdown that commenced in March 2020, while the profession and service-users were coming to terms with its vast implications, the Occupational Therapy Association of South Africa initiated a Webinar series that stimulated provocative discussions and difficult dialogues. The authors of this paper deliver a commentary, critically engaging with the challenges of cogently articulating the contribution of occupational therapy services across various sectors of service delivery during the first wave of the Covid-19 pandemic in South Africa. The challenges of on the one hand, negotiating the abrupt cessation of rehabilitation services, especially in the public sector and, on the other, advancing the reasoning for accessible, community-based services, are considered. Aim: The commentary draws from presentations at and reflections on the webinar hosted on 24 June 2020 titled 'Ethical and Moral Challenges for Occupational Therapy'. In this paper, the competing ethical and moral issues arising from being urged to adopt different ways of thinking and doing occupational therapy during the Covid-19 lockdown are outlined.

Proposition: It is suggested that experiences emerging from this pandemic are urging the profession to rethink its positionality in the health sector. Two main considerations deserve attention: The first is rethinking how we use occupational therapy knowledge to act from and in relation to local contexts, viewing people who are marginalised as knowledge and action partners through generative disruption. The second is to revisit what it entails to foster a posture that acknowledges human dignity.

Conclusion: Generative disruption includes a continuous and unabashed critical reflection of and on the limits of our practice and knowledge at hand. It means that we need to include service users and community partners in taking necessary steps to render services in local contexts most needed in recalibration toward social and occupational justice. In our knowledge-making partnerships, it is also imperative to revisit the posture of acknowledging human dignity.

Keywords: Covid- 19; occupational therapy; occupational justice; human dignity; generative disruption

\section{INTRODUCTION}

The Covid-19 pandemic significantly exposed the heavy burden of institutional racism and social inequality in societies ${ }^{1,2}$. This led to challenges for Health professions, including occupational therapy ${ }^{3}$, as discussed in one of the 2020 online webinar sessions organised by the Occupational Therapy Association of South Africa (OTASA). The June 2020 session on "Covid- I 9 Ethical and Moral challenges for Occupational Therapy" presented a moment for reflexivity where the many competing and urgent moral demands foregrounded by the Covid-19 pandemic, could be considered. This commentary captures the essence of the two presentations, highlighting the challenges in conceptualising contextually relevant occupational therapy services that were brought into stark contrast during the Covid- 19 pandemic during the first few months of 2020.

In presentations at this webinar, two of the presenters, namely the co-authors of this commentary, invited re-thinking of the traditional use of knowledge in the profession and embracing an openness to different ways of knowing in occupational therapy. The goal of this re-thinking and openness was to highlight the potential of collective action in local contexts, with marginalised people as both knowledge and action partners. The possibilities articulating why and how occupational therapy operates in a cogent way within the context of community-based practices, were explained. The robust discussion that ensued following the presentations, illustrated a need to channel the sense of urgency for more accessible and relevant occupational therapy services to marginalised communities as well as the importance of revisiting what it means to practise human dignity.

Framing the need for human dignity, accessible and equitable services: Magnified injustices along societal fault lines Notwithstanding the beleaguered socio-economic and political challenges this country is facing post-apartheid, the South African Constitution and Bill of Human Rights may still be regarded as "the most admirable constitution in the history of the world"4:261. Some main reasons being that it immediately espouses redressing fundamental inequalities of the past, but also protects citizens from unfair discrimination on any grounds ${ }^{5,6}$. The Bill of Human Rights is a "cornerstone of democracy"6:5 and consists of three pillars: equality, freedom, and human dignity ${ }^{6}$. Human dignity not only runs as a golden thread through the Constitution as both a non-derogable right and a value ${ }^{7}$, but it also forms the centre point of equality, 
regardless of differentiating categories such as race, gender, disability, or age ${ }^{6}$. Partly because of the tenacious historical markers of injustice, seemingly discursively iterating themselves in the past 27 years post-apartheid ${ }^{8}$, there has been an awareness that we live in a context where equity and justice remain to be everyday challenges for people along the fault-lines of race, disability, socio-economic, and gender descriptors. However, Covid-19 brought into plain view how a priori inequalities along these fault-lines exponentially exacerbate the burdens that marginalised and oppressed people globally endure.

As evidence, internationally, the killing of George Floyd has led to renewed attention to the calls for anti-racism, as emanating from the Black Lives Matter movement. Likewise in 2020 in South Africa, we have seen the fatal consequences of police brutality on people such as Collins Khosa ${ }^{9}$ on his property, Robyn Montsumi while in custody ${ }^{10}$ and the ruthless shooting of Nathaniel Julies, a teenager with Down's syndrome" . This, together with the disregard for human dignity and wellbeing shown for the daily struggles faced by marginalised communities during the initial lockdown and later the first peak of the pandemic in South Africa has been evident in the evictions of shack dwellers across the country ${ }^{12-14}$. Furthermore, the approach to dealing with the needs of people living on the streets ${ }^{15}$ as well as the continuous inept handling of the pervasive prevalence of Genderbased Violence (GBV) ${ }^{16}$ shows the everyday shattering impact of a perpetually flawed systems. In addition, the inequality occurring as schools re-opened ${ }^{17}$ in 2020 was evident of how human rights and equality tend to be affected. This effect was also demonstrated in the impact of unemployment on food security and the lack of access to water at a time when this is needed to preserve life and wellbeing ${ }^{18}$. On a governance level, all the above were compounded by increasingly emerging evidence of widespread corruption and exploitation of relief-funds. On the one hand, from an occupational perspective, one may argue that some of these exploitations for monetary reasons are generated in lieu of the social field of occupational choice ${ }^{19}$, or a lack of occupational possibilities ${ }^{20}$. On the other hand, employing the same argument to justify or mitigate corrupt and/or criminal actions by people in governing positions of political and economic power, will not stand. Not from a judicial, ethical, moral, or an occupational justice perspective.

At the forefront of healthcare in a time of crisis, the occupational therapy profession too was again confronted with the limits of its practice, if not its difficulty to articulate collectively the profession's value and purpose within the rationale of a medical model. At most public hospitals, outpatient rehabilitation services ceased and the turn-around times for admission and discharge of acute-care patients rendered occupational therapy services moot. The call for the occupational therapy profession to contribute to opposing these issues that not only affect people's health and wellbeing but often leads to stress, health conditions and disabilities of various forms, is embedded in a justice and socially transformative orientation to occupational therapy ${ }^{21}$. Redesigning occupational therapy services to become more contextually relevant through re-orientating these services and making them accessible to and in community settings, is pivotal to this discourse.

Towards human dignity and accessible, equitable services A posture of acknowledging a person's human dignity is fundamental to contextually relevant services. The posture toward acknowledging a person's human dignity, as inherent in the South African Constitution and National Health $\mathrm{Act}^{22}$, can be recognised in several ways. One is to inherently regard any person we encounter as an equal and legitimate carrier of, and giver of knowledge $\mathrm{e}^{23-25}$ and thereby, recognising the person's epistemic virtue. Ndlovu- Gatsheni ${ }^{26}$ states that one form of dehumanisation is when one rejects a person's epistemic virtue, meaning that one can often, sometimes in quite unsaid and tacit ways, render another person as either having no knowledge, or knowledge of a lesser value ${ }^{26}$. For example, users of occupational therapy services, may not have the same knowledge as occupational therapists, and yet may have crucial knowledge that needs to be communicated to deliver effective and relevant services. A second way a posture that acknowledges human dignity can be recognised, is to maintain an ego-state from one adult to another when we communicate with adult service users. That means that the priority should be to avoid adopting communicative ways that assume a paternalistic posture, especially when a person speaks a language that is different to that of the professional, is elderly, has less formal education, or is a person with a disability. Regarding a person as an equal adult and not as a quasi-child is imperative when we engage in reasoning and knowledge exchange. A third way of maintaining a posture that acknowledges human dignity is to include all relevant stakeholders in decision-making. This may imply that decision-making is often a process and requires one to keep asking questions and to be comfortable with the fact that as an occupational therapist, one does not know or must know everything. Moreover, we need to be careful of assuming that we always know best, as this masks another form of paternalism ${ }^{8}$.

The re-orientation and redesign of occupational therapy will be emboldened through collaborating with community health workers and community members while focusing on systemic issues ${ }^{27,28}$. Some of the lessons learned during the peak of the Covid-19 pandemic highlight the need to respond to this moral responsibility to contribute to community-driven strategies that reduce poverty and inequality and challenge the systems that maintain inequities. Such approaches support and extend the work already being done in communities. While there may be many individual, even personal actions taken to respond to people's needs, there is also the opportunity to galvanize our actions by critically reflecting on the gaps and approaches to the services that we provide, so that these services become more accessible. This is supported by the expectation that as health professionals, we focus on the social determinants of health ${ }^{21}$ as guided by the marginalised people in the contexts where we envisage our practice. This could assist in acting from where we are, such that we may change what we do as health professionals. Scholarship in occupational science and occupational therapy is available and offers some ideas on the necessary shifts so that the discipline of occupational science and the profession of occupational therapy may respond more cogently to the global and local economic, social and political factors that contribute to occupational injustice by limiting human engagement in occupations. Responding to occupational injustice through service provision is implicit in OTASA's submission to the Truth and Reconciliation Commission in $1997^{29}$ and more recently, the Association's expression of our collective commitment to standing in solidarity in ending systemic racism and forms of oppression ${ }^{30}$. To illustrate what acting from where you think and do from could look like, we describe a contribution emanating from academia during the lockdown.

\section{Challenging the status quo through generative disruption} Generative disruption involves the profession continuously questioning where it is that we think from, that is, to consider the influence of our geo-location and positionality on knowledge production and consumption, so that we ensure that we shift to thinking 
from positions where we utilize or seek knowledge that allows us to take actions that promote equity and justice ${ }^{31}$. In essence, this means challenging systemic and interpersonal oppression, as it occurs in our everyday occupations so that taken-for-granted hegemonies related to race, ableism, gender, or similar discriminatory practices are questioned. We will be able to shift our practices to do this through critical reflexivity on how privilege and oppression operate through what is known, through how we see one another as beings, and through what we do in the contexts that we find ourselves in. Such critical reflexivity is emboldened when we focus on the (occupational) contexts within which people live. So, while occupational therapists may be called upon to assist in acute care during Covid-19, we can also look to serve the many people who will not access hospital-based care. Many Community Health Workers, volunteers, and people in communities need support and guidance to assist with designing solutions and accessing resources, as they face the everyday burdens of social inequality and occupational and epistemic injustice. It is here that occupational therapists could be useful resources available to communities during this time. While we do this, we can also learn how to change our practice in the long-term to respond to the needs as we come to understand them more. The Occupation-based Community Development framework ${ }^{32,33}$ provides some guidance on how to engage in change-processes in ways that respect how the histories of marginalized people have been shaped by dominating geopolitical, economic, and social factors, and how these factors influence occupational engagement during Covid-19. Through doing praxis that uses participatory action-learning methodologies and de-colonial perspectives, we can generate questions that will fuel our practice. Our work is now to open possibilities for more equitable spaces of action to emerge. While there are many possibilities for how to do this, two examples are: Occupational therapists could be available through existing governmental call centres to deal with people calling in for advice on gender-based violence, also offering specialized guidance to persons with disabilities and their caregivers. Occupational therapists could also be available as resource persons at district levels to mental health service users (MHSUs), their families, and communities who are trying to assist MHSUs in their communities. Of course, if we redeployed some of our services from tertiary levels of care to district levels, it would mean that services would be much more accessible and this, together with redesigning services so that we include a focus on injustice, would position the profession to serve during and post the Covid- 19 pandemic. Furthermore, if at district levels we shifted from focusing on clinical services, there are many possibilities for how to re-imagine practice in these times.

With the vision of a more disability inclusive health system, the first author, as part of a research group with colleagues and disability advocates in Inclusive Practices Africa, urged the Presidency and the Department for Women, Youth and Persons with Disability and Social Development to motivate for mainstreaming the inclusion of disability into planning for Covid- 19 responses. We proposed that resources be mobilised to support persons with disabilities, their families, and communities in multiple ways. Through a series of implementation practices (for example, advocacy meetings with key decision-makers and communicating key messages of how disability intersects with societal issues such as Gender-Based Violence) we saw some inclusion of disability in the 'languaging' and planning for Covid-19 in the presidency and various governmental departments. This was evident in the president's third address to the nation where he identified the specific needs of persons with disabilities more explicitly. While this advocacy made a small contribution, adding to the voices of the many Non-Profit Organisations (NGOs) and persons with disabilities already advocating, much more needs to be done, especially with regards to the implementation of accessible services. Health and rehabilitation professionals could be more available to contribute at district levels, advocating for the re-direction of services from acute and tertiary care, towards communities. In addition, for people accessing services in the private sector, more services which connect with their home environments and supports are needed. We cannot afford to be silent or absent from creating disability-inclusive services. Unfortunately, we know what the consequences of the poor state of service provision have been for people with disabilities on the margins, as evidenced in the case of Life Esidimeni ${ }^{34}$.

While the OTASA Truth and Reconciliation Commission submission in 1997 acknowledged the "profession's preference to not be involved in politics"29:19, the current OTASA statement signals that this preference - together with trying to be neutral and silent in the face of inequity and oppression - is intolerable ${ }^{30}$. Implicit to this is the need to de-link from the systems of thinking that hold us captive to complying with bio-medially oriented systems and systems that marginalise groups of people ${ }^{31}$. This concept of de-linking has been identified as being a part of generative disruption and draws from the decolonial scholarship of Walter Mignolo, who writes that delinking from coloniality is an ideological and a pragmatic project ${ }^{35,36}$.

\section{CONCLUSION}

Embracing generative disruption is about being open to not knowing and learning to know through collaborating with marginalised people. This means that we will need to become accepting of not always having solutions at the outset and instead, rethink and codesign our services so that we collaborate with people who are oppressed and marginalised. Revisiting the posture of acknowledging and practising human dignity means that we need to consciously interrogate the extent to which we unconditionally accept a person's inherent epistemic virtue; view service users as legitimate bearers and sharers of knowledge; interact from one adult to another in our knowledge-exchanges and include service users in what is often a process of decision-making. In this moment, and again postCovid-19, we need to seize the chance to practice in ways that support participation in occupations more equitably. It means using our expertise in service in ways that respond to people's needs in their contexts. We can do this by working with organisations and movements already active, such as the C-19 People's Coalition, people we can partner with and learn from.

\section{REFERENCES}

I. Karmakar M, Lantz PM, Tipirneni R. Association of Social and Demographic Factors With COVID-19 Incidence and Death Rates in the US. JAMA Network Open. 202 I; 4: I e2036462.

https://jamanetwork.com/journals/jamanetworkopen/fullarticle/2775732

2. Oliveira RGD, Cunha APD, Gadelha AGDS, Carpio CG, Oliveira RBD, Corrêa RM. Desigualdades raciais e a morte como horizonte: considerações sobre a COVID-19 e o racismo estrutural. Cadernos de Saúde Pública. 2020; 36(9).

http://dx.doi.org/10.1590/0102-31 Ix00150120

3. Hoel V, Zweck CV, Ledgerd R. The impact of Covid- 19 for occupational therapy: Findings and recommendations of a global survey. World Federation of Occupational Therapists Bulletin. 2021; I-8. https://doi.org// 0.1080/14473828.2020.1855044 
4. Sustein CR. Designing Democracy: What Constitutions Do. New York: Oxford University Press. 200I.

5. Fisher R. A Progressive Constitution. Business Day Human Rights Day. [Internet] 2021 ; n.d.

https://businessmediamags.co.za/xtrending/a-progressive-constitution/

6. South African Constitution, Chapter 2, Bill of Rights. South African Department of Justice, 202I(1996).

https://www.justice.gov.za/legislation/constitution/pdf.html

7. Wessels L. Personal interview: Grounding principles in the SA Constitution and Bill of Human Rights for ethical decision making during the COVID-19 pandemic. Advocate Leon Wessels was one of the co-writers in the construction of the SA Constitution and Bill of Human Rights. 2020; 20 June.

8. Rauch van der Merwe, T. The Political Construction of Occupational Therapy in South Africa: A Critical Analysis of Curriculum as Discourse. Bloemfontein: University of the Free State; 2019. http:// hdl.handle.net/ I I660/10424

9. Nicolson G. Eight witnesses saw soldiers assault Collins Khosa - IPID report. Daily Maverick [Internet]. 2020; 15 September 2020. https:// www.dailymaverick.co.za/article/2020-06- I0-eight-witnesses-sawsoldiers-assault-collins-khosa-ipid-report/

10. Grobler R. Police watchdog investigating 'baffling' death of sex worker while in custody. News24 [Internet]. 2020; 15 September 2020. https://www.news24.com/news24/southafrica/news/policewatchdog-investigating-baffling-death-of-sex-worker-while-incustody-20200603

II. Wikipedia. Shooting of Nathaniel Julies South Africa. [Internet] 2020. https://en.wikipedia.org/wiki/Shooting_of_Nathaniel_Julies

12. Draper A, Philpott G, Ntseng D, Butler M. Durban shack dwellers illegally evicted. New Frame [Internet]. 2020; 23 June. https://www. newframe.com/ethekwini-shack-dwellers-illegally-evicted/

13. Serebrin J. In South Africa's cities, evictions are happening despite a national ban. City Monitor [Internet]. 2020; 15 September 2020. https://www.citymetric.com/fabric/south-africas-cities-evictionsare-happening-despite-national-ban-5226

14. Bonono MG. Undeterred by evictions, South Africa's Abahlali baseMjondolo continues struggle. [internet] Peoples Dispatch; 2020; 4 August. https://peoplesdispatch.org/2020/08/04/undeterred-byevictions-south-africas-abahlali-basemjondolo-continues-struggle/

15. Kiewit L. Inside Strandfontein: Cape Town's COVID-19 homeless site. Mail and Guardian [Internet]. 2020; 15 September. https:// mg.co.za/article/2020-04-16-inside-strandfontein-cape-townscovid-19-homeless-site/

16. Tracey-Temba L. Police and courts must do more to reduce genderbased violence. ISS Today [Internet]. 2020; 17 September. https:// issafrica.org/iss-today/police-and-courts-must-do-more-to-reducegender-based violence?utm_source=BenchmarkEmail\&utm_ campaign $=$ ISS_Today\&utm_medium $=$ email.

17. Dougan L. Widening inequality gap in SA schooling a further casualty of Covid-19. Daily Maverick [Internet], 2020; 30 July.

https://www.dailymaverick.co.za/article/2020-07-30-wideninginequality-gap-in-sa-schooling-a-further-casualty-of-covid-19/

18. Zembe-Mkabile W, Ramokolo V, Doherty T. Covid-19 and social grants: Relief measures welcome, but not enough. Daily Maverick [Internet]. 2020; 15 September. Available from:

https://www.dailymaverick.co.za/article/2020-05-26-covid-19-andsocial-grants-relief-measures-welcome-but-not-enough/

19. Galvaan R. The Contextually Situated Nature of Occupational Choice: Marginalised Young Adolescents' Experiences in South Africa. Journal of Occupational Science. 2015.

https://doi.org/10.1080/14427591.2014.912124
20. Laliberte Rudman D. Occupational terminology, occupational possibilities. Journal of Occupational Science. 2010; 17: 55-59. https://doi.org/I0.1080/I4427591.2010.9686673

21. Richards LA, Galvaan R. Developing socially transformative practice in Occupational Therapy: insights from South African practice. South African Journal of Occupational Therapy. 2018; I(I): 3-8. http://dx.doi.org/I0.17/59/23 I0-3833/20I7/vol48n la2

22. National Health Act $6 \mathrm{I}$ of 2003. https://www.gov.za/documents/national-health-act\#

23. Fricker M. Epistemic Injustice, Power and the Ethics of Knowing. Oxford: Oxford University Press; 2007.

24. Mutanga O, Walker M. Towards a Disability-inclusive Higher Education Policy through the Capabilities Approach. Journal of Human Development and Capabilities. 2015; 16(4): 50I-I7. https://doi.org/10.1080/19452829.2015.1101410

25. Walker M. Failures and Possibilities of Epistemic Injustice, with some implications for Higher Education. Critical Studies in Higher Education. 2018; 1- 17. https://doi.org// 0.1080/17508487.2018.1474774

26. Ndlovu-Gatsheni SJ. Decoloniality as the Future of Africa. History Compass. 20I5; I3 (I0): 485-96. https://doi.org/I0.1 I I I/hic3.12264

27. van Dyk J. Community health workers - could COVID finally unlock their role in the NHI? Bhekisa Centre for Health Journalism. 2020.

28. Pillay M, Kathard H. Renewing Our Cultural Borderlands Equitable Population Innovations for Communication (EPIC). Topics in Language Disorders. 2018; 38(2): 143-60. https://doi.org//0.1097/TLD.0000000000000 I5 I

29. Occupational Therapy Association South Africa. The Truth and Reconciliation Commission. Submission from the Occupational Therapy Association of South African to the TRC's Health Sector, 10 September 1997. South African Journal of Occupational Therapy 1998; 27:2. Available from:

http://www.scielo.org.za/scielo.php?script $=$ sci arttext\&pid=S23 10-38332008000200005\&lng=en.

30. Occupational Therapy Association of South Africa. OTASA Statement on Systemic Racial Oppression and a Call to the Occupational Therapy Community. Available from:

https://m.facebook.com/OTAssociationOfSouthAfrica/photos/a.72 $9721850472759 / 2837698593008397 /$ ?type $=3 \&$ source $=54$.

31. Galvaan R. Generative disruption through occupational science: Enacting possibilities for deep human connection. Journal of Occupational Science. 2020: I- 13. https://doi.org//0.1080/14427591.2020.1818276

32. Galvaan R, Peters L. Occupation-based Community Development: A critical approach to Occupational Therapy. In: Dsouza S, Galvaan R, Ramugondo E, editors. Concepts in Occupational Therapy: Understanding Southern Perspectives. Manipal: Manipal University Press; 2017: 172-87.

33. Galvaan R, Peters L. Occupation-based Community Development: A critical approach to Occupational Therapy. In: Dsouza S, Galvaan R, Ramugondo E, editors. Concepts in Occupational Therapy: Understanding Southern Perspectives. Manipal: Manipal University Press; 2017: 172-87.

34. Makgoba M. The report into the 'circumstances surrounding the deaths of mentally ill patients: Gauteng Province' No Guns: 94+ Silent Deaths and still counting. 2019. http://healthombud.org.za/ wp-content/uploads/2017/05/FINALREPORT.pdf

35. Mignolo W. Delinking: The rhetoric of modernity, the logic of coloniality and the grammar of de-coloniality. Cultural studies. 2007;2I(2-3):449-5 I4.

https://doi.org/10.1080/0950238060। I62647 
36. Mignolo W. The darker side of western modernity: Global futures, decolonial options: Duke University Press; $201 \mathrm{I}$.

\section{Corresponding Author:}

* Roshan Galvaan

Email: roshan.galvaan@uct.ac.za 